\title{
Management of Stridor in Paediatric Population- Our Experience
}

\author{
Shivali Thakur ${ }^{1}$, Sanajeet Kumar Singh ${ }^{2}$, Ravi Roy ${ }^{3}$, Rajeev Chugh ${ }^{4}$, Devendra Kumar Gupta ${ }^{5}$, Sunil Goyal ${ }^{6}$, Seema Pati ${ }^{7}$ \\ ${ }^{1}$ Department of ENT, Army Hospital Research and Referral, New Delhi, India. ${ }^{2}$ Department of Otorhinolaryngology, \\ Army Hospital Research and Referral, New Delhi, India. ${ }^{3}$ Department of Otorhinolaryngology, Army Hospital Research \\ and Referral, New Delhi, India. ${ }^{4}$ Department of Otorhinolaryngology, Army Hospital Research and Referral, New Delhi, \\ India. ${ }^{5}$ Department of Otorhinolaryngology, Army Hospital Research and Referral, New Delhi, India. ${ }^{6}$ Department of \\ Otorhinolaryngology, Army Hospital Research and Referral, New Delhi, India. ${ }^{7}$ Department of ENT, Army Hospital \\ Research and Referral, New Delhi, India.
}

\section{ABSTRACT}

\section{BACKGROUND}

Stridor is a common presentation in paediatric ENT OPDs.(1) There can be numerous causes of stridor in this age group- congenital and acquired.(2) There are various methods available for diagnosis of such cases- radiological, rigid laryngotracheobronchoscopy and fibreoptic laryngoscopy.(3) The approach to such a case and its subsequent management varies from case to case.(4) Treatment strategy for each possible cause varies. There are very few case series in Indian population reporting such cases. In our tertiary care centre, we come across many cases with stridor. Their subsequent evaluation leads us to diagnosis. At times, upper airway evaluation is normal. The management then depends on specific aetiology. We are describing our case series comprising 15 patients with various diagnosis and subsequent management.

\section{METHODS}

This is a case series comprising 15 patients. This is a prospective study carried out at our tertiary care centre. The variety of cases included laryngomalacia, retropharyngeal abscess and subglottic stenosis which were managed as per existing guidelines.

\section{RESULTS}

The outcomes of our series were quite promising with $93.33 \%$ children successfully decannulated.

\section{CONCLUSIONS}

The management of a child with stridor is a challenge for the treating team. We should keep in mind that every paediatric case of stridor does not imply an underlying pathology. A systematic approach and keeping all the possible differential diagnoses in mind are the most important steps in achieving optimum results.

\section{KEYWORDS}

Stridor, Laryngomalacia, Subglottic Stenosis, Fibreoptic Laryngoscopy, Rigid Bronchoscopy
Corresponding Author:

Dr. Shivali Thakur,

Department of ENT- HNS,

Army Hospital Research and Referral,

Delhi Cantt-110010, India.

E-mail: shivalibnol81@gmail.com

DOI: 10.14260/jemds/2019/783

Financial or Other Competing Interests: None.

How to Cite This Article:

Thakur S, Singh SK, Roy $R$, et al. Management of stridor in paediatric population- our experience. J. Evolution Med. Dent. Sci. 2019;8(48):3631-3634, DOI: 10.14260/jemds/2019/783

Submission 02-08-2019,

Peer Review 11-11-2019,

Acceptance 19-11-2019,

Published 02-12-2019. 


\section{BACKGROUND}

Stridor is a common presentation in paediatric ENT OPDs.(1) There can be numerous causes of stridor in this age groupcongenital and acquired.(2) There are various methods available for diagnosis of such cases- radiological, rigid laryngotracheobronchoscopy and fibreoptic laryngoscopy.(3) The approach to such a case and its subsequent management varies from case to case.(4) Treatment strategy for each possible cause varies. In cases of laryngomalacia, supraglottoplasty has got good results and parents satisfaction.(5) This also leads to better quality of life in terms of overall health, growth, development, weight gain and parents expectations.(6) There are various studies which define and compare the various approaches available for treatment of subglottic stenosis. $(7,8,9)$ There has been many case series in literature describing deep neck space abscesses in children below 5 years of age and their complications.(10) Some of the causes are associated with some syndromes.(11) There are very few case series in Indian population reporting such cases. In our tertiary care centre, we come across many cases with stridor. Their subsequent evaluation leads us to diagnosis. At times, upper airway evaluation is normal. The management then depends on specific ethology. We are describing our case series comprising 15 patients with various diagnosis and subsequent management. Some of them had no abnormality upon evaluation.

We wanted to analyse the various presentations of a stridulous child and the various treatment options available.

\section{METHODS}

This is a case series comprising 15 patients. This is a prospective study carried out at our tertiary care centre. The detailed description of cases are as follows.

Case 1- 03 1/2 Month old male Child presented with c/o noisy breathing since day 08 of life. Child was born by Full term normal vaginal delivery, breast fed and immunised. Clinically, patient had stridor on crying which reduced on rest. NCCT done at peripheral hospital was reported as narrowing of subglottis at level of C3-4 for a length of $6.5 \mathrm{~mm}$ with collapse of lumen. fibreoptic laryngoscopy done at our centre revealed omega shaped epiglottis, (R) arytenoid and AE Fold falling over glottis, sub glottis was normal. Based on our findings NCCT images were reviewed at our tertiary centre which did not show any subglottis narrowing. Diagnosis of laryngomalacia was made. Pt subsequently underwent supraglottoplasty and (R) AE fold released and laserised using supra pulse continuous $8 \mathrm{~W}$ power $\mathrm{CO}_{2}$ laser. Pt was kept intubated and on ventilator for 72 hours. Extubation was done in OT in controlled settings and patient did fine after that. 03 more patients were detected, diagnosed and treated as a case of laryngomalacia. All were less than 03 months of age, one male and rest female. The male patient had congenital cardiac anomaly also.

Case 2- Two-and-a-half-month-old male child presented with c/o cough and noisy breathing of 10 days duration. The child was born by FTNVD, breastfed and well immunised with no $\mathrm{H} / \mathrm{O}$ tuberculosis contact. Initially managed as wheeze associated respiratory infection at peripheral hospital. Child was intubated, tracheostomy was done in view of prolonged intubation, however there was difficulty in decannulation following which child was referred to our tertiary referral hospital for further management. Initially child was managed with iv antibiotics in view of leucocytosis and standard tracheostomy tube care. Chest X-ray revealed soft tissue density in retropharyngeal space extending from $\mathrm{C} 2-4$. The child was taken up for examination under anaesthesia on same day. DLscopy was done which revealed distinct fluctuating smooth bulge in posterior pharyngeal wall, needle aspiration was done- $30 \mathrm{ml}$ pus was drained, cruciform incision was given transorally to drain residual pus. FOB was done, airway was clear till carina. Child was continued on iv antibiotics for 05 days and check FOL revealed no residual abscess. Child was successfully decannulated and sent home. 01 more patient was diagnosed and treated as a case of retropharyngeal abscess. The child was 4 months old and female.

Case 3-2-month male old child presented with c/o noise breathing and feeding difficulty since birth. The child was born by FTND, breastfed and immunised. CT scan at peripheral hospital was reported as B/L choanal atresia. The child was referred to our tertiary centre for further management. On clinical examination, size 6 infant feeding tube could be passed through both nostrils. FOL revealed normal upper airway, scope could be easily negotiated through both nostrils. Diagnosis of B/L choanal atresia was ruled out. Upper airway was normal. 04 more patients presenting with stridor were evaluated and found to have a normal upper airway. 01 patient presented with thermal burns in oropharynx and upper airway evaluation was done to rule out any laryngeal burns which was normal.

Case 4- A 3-year-old male child, a k/c/o ARDS, on tracheostomy tube presented to our tertiary centre for decannulation. On evaluation at our centre, FOL revealed circumferential stenotic segment $01 \mathrm{~cm}$ below vocal cords. $\mathrm{Pt}$ underwent airway evaluation and $\mathrm{CO}_{2}$ laser assisted excision of subglottic stenosis with serial balloon dilatation -two sittings at 3-month interval. Subsequently patient was successfully decannulated. 02 other cases were similarly treated. The consolidated data is given in table 1.

\section{RESULTS}

Out of 15 children, majority ( $60 \%$ ) were males. The age group of patients were ranging between 2 months to 4 years with mean age of 11.25 months. Out of 15 patients, 07 (46.66\%) children had comorbidities such as ARDS, Croup, VSD, cleft lip. As far as presenting complaints were concerned, $86.66 \%$ presented with some form of stridor, $13.33 \%$ (02 patients) presented with failure to decannulate and $6.6 \%$ (01 patient) presented with fever. After evaluation, $40 \%$ children were found to be having no upper airway abnormality. $26.66 \%$ were diagnosed as laryngomalacia, $20 \%$ as subglottic stenosis and $13.33 \%$ as retropharyngeal abscess. All cases were treated as per standard treatment guidelines. Children were followed for a period of 01 year after completion of treatment. The outcomes of our series were quite promising with $93.33 \%$ children successfully decannulated. Few representative images are shown in Fig-1-5. 


\begin{tabular}{|c|c|c|c|c|c|c|c|c|}
\hline Name & Age & Sex & Comorbidities & Presenting Complaints & Diagnosis & Treatment & Decannulation & $\begin{array}{l}3 \text { Mon. } \\
\text { Follow Up }\end{array}$ \\
\hline Naman & \begin{tabular}{|c|}
3.5 \\
months
\end{tabular} & M & Nil & $\begin{array}{c}\text { Stridor in supine position, } \\
\text { improving in prone position }\end{array}$ & $\begin{array}{l}\text { Laryngomalacia- } \\
\text { Grade III }\end{array}$ & $\begin{array}{c}\text { Laser assisted supraglottoplasty } \\
\text { (8 W Suprapulse continuous } \mathrm{CO}_{2} \text { laser) }\end{array}$ & $\begin{array}{l}\text { Extubation } \\
\text { after } 72 \mathrm{hrs}\end{array}$ & Asymptomatic \\
\hline Prince & \begin{tabular}{c|}
2.5 \\
months
\end{tabular} & M & PDA & $\begin{array}{c}\text { Stridor in supine position, } \\
\text { improving in prone position }\end{array}$ & $\begin{array}{l}\text { Laryngomalacia- } \\
\text { Grade III }\end{array}$ & $\begin{array}{c}\text { Laser assisted supraglottoplasty } \\
\text { (8 W Suprapulse continuous } \mathrm{CO}_{2} \text { laser) }\end{array}$ & Not achieved & $\begin{array}{c}\text { Decannulation } \\
\text { achieved }\end{array}$ \\
\hline \begin{tabular}{c|}
$\mathrm{P}$ \\
Rishita
\end{tabular} & \begin{tabular}{|c|}
2 \\
months \\
\end{tabular} & $\mathrm{F}$ & Nil & $\begin{array}{c}\text { Stridor in supine position, } \\
\text { improving in prone position }\end{array}$ & $\begin{array}{l}\text { Laryngomalacia- } \\
\text { Grade III }\end{array}$ & $\begin{array}{c}\text { Laser assisted supraglottoplasty } \\
\text { (8 W Suprapulse continuous } \mathrm{CO}_{2} \text { laser) }\end{array}$ & Achieved & Asymptomatic \\
\hline Mayuri & \begin{tabular}{|c|}
2.8 \\
months
\end{tabular} & $\mathrm{F}$ & Nil & $\begin{array}{l}\text { Stridor in supine position, } \\
\text { improving in prone position }\end{array}$ & $\begin{array}{l}\text { Laryngomalacia- } \\
\text { Grade II }\end{array}$ & $\begin{array}{c}\text { Laser assisted supraglottoplasty } \\
\text { (8 W Suprapulse continuous } \mathrm{CO}_{2} \text { laser) }\end{array}$ & Achieved & Asymptomatic \\
\hline Umesh & \begin{tabular}{|c|}
2.5 \\
months
\end{tabular} & M & Nil & URTI and stridor on exertion & $\begin{array}{l}\text { Retropharyngeal } \\
\text { abscess }\end{array}$ & Incision \& Drainage & Achieved & Asymptomatic \\
\hline Nisha & \begin{tabular}{|c|}
4 \\
months
\end{tabular} & $\mathrm{F}$ & Nil & Fever & $\begin{array}{l}\text { Retropharyngeal } \\
\text { abscess }\end{array}$ & Incision \& Drainage & Achieved & Asymptomatic \\
\hline David & \begin{tabular}{c|}
2 \\
months
\end{tabular} & M & Cleft lip & $\begin{array}{l}\text { Stridor on exertion and } \\
\text { feeding difficulty }\end{array}$ & Upper airway-NAD & Evaluation-NAD & Achieved & Asymptomatic \\
\hline Sarthak & \begin{tabular}{c|}
2 \\
years
\end{tabular} & M & $\begin{array}{l}\text { Thermal burns } \\
\text { oropharynx }\end{array}$ & $\begin{array}{l}\text { Intermittent } \\
\text { Stridor }\end{array}$ & Upper airway-NAD & NAD & Achieved & Asymptomatic \\
\hline Bhavya & \begin{tabular}{|c|}
2.5 \\
months \\
\end{tabular} & $\mathrm{F}$ & Nil & Intermittent Stridor & Upper airway-NAD & NAD & Achieved & Asymptomatic \\
\hline Ritwik & \begin{tabular}{|c|}
3 \\
months
\end{tabular} & M & VSD & Intermittent Stridor & Upper airway-NAD & NAD & Achieved & Asymptomatic \\
\hline Ravish & 1 year & $\mathrm{M}$ & Nil & Intermittent Stridor & Upper airway-NAD & NAD & Achieved & Asymptomatic \\
\hline Manisha & \begin{tabular}{|c|}
6 \\
months \\
\end{tabular} & $\mathrm{F}$ & GBS & Intermittent Stridor & Upper airway-NAD & NAD & Achieved & Asymptomatic \\
\hline Armaan & 3 year & M & ARDS & $\begin{array}{l}\text { failure to } \\
\text { decannulate }\end{array}$ & \begin{tabular}{|c|}
$\begin{array}{c}\text { Subglottic Stenosis } \\
\text { (Grade III) }\end{array}$ \\
\end{tabular} & $\begin{array}{c}\text { Laser assisted excision and serial balloon (10 } \\
\text { mm diameter) dilatation-02 sittings }\end{array}$ & Achieved & Asymptomatic \\
\hline Aman & 4 years & M & Croup & Intermittent Stridor & $\begin{array}{c}\text { Subglottic Stenosis } \\
\text { (Grade III) }\end{array}$ & $\begin{array}{c}\text { Laser assisted excision and serial balloon (10 } \\
\text { mm dimeter) dilatation- } 03 \text { sittings }\end{array}$ & Achieved & Asymptomatic \\
\hline Dixi & $\begin{array}{c}1.5 \\
\text { years }\end{array}$ & $\mathrm{F}$ & ARDS & $\begin{array}{l}\text { Failure to } \\
\text { decannulate }\end{array}$ & $\begin{array}{c}\text { Subglottic Stenosis } \\
\text { (Grade II) }\end{array}$ & $\begin{array}{l}\text { Laser assisted excision and balloon dilatation } \\
(08 \mathrm{~mm} \text { diameter })-01 \text { Sitting }\end{array}$ & Achieved & Asymptomatic \\
\hline \multicolumn{9}{|c|}{ Table 1. Consolidated Data } \\
\hline
\end{tabular}

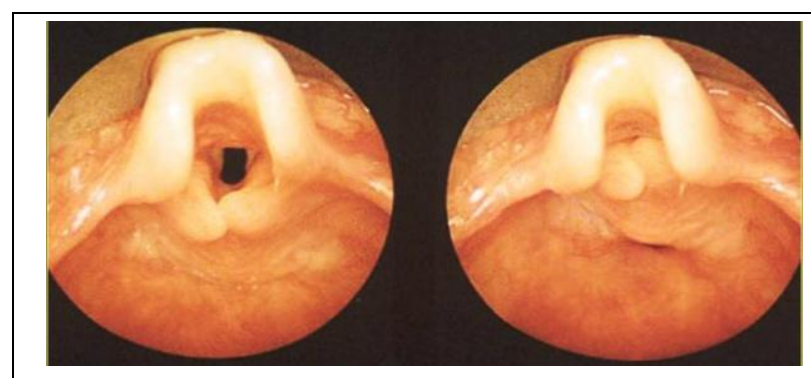

Figure 1. Laryngomalacia

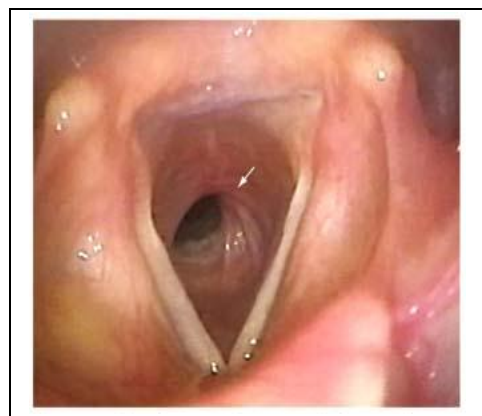

Figure 2.

Subglottic Stenosis

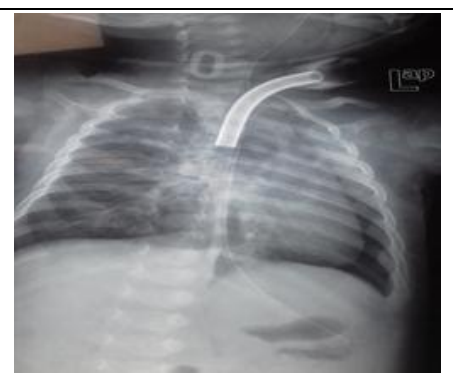

Figure 3.

Retropharyngeal Abscess

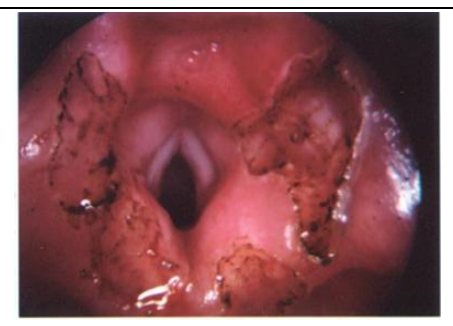

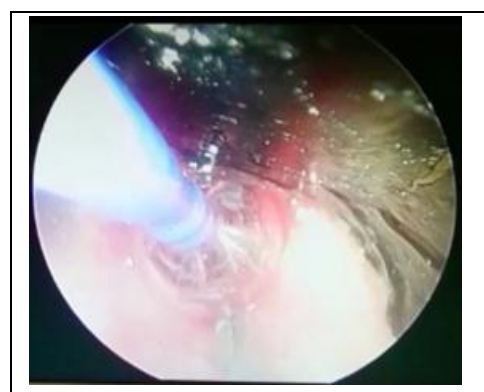

Figure 5.

Balloon Dilatation

\section{DISCUSSION}

In our case series of 15 paediatric airway cases, all were successfully treated. We managed a variety of cases- 04 cases of laryngomalacia, 03 cases of subglottic stenosis and 02 cases of retropharyngeal abscess. 05 cases presenting with stridor were evaluated and found to have a normal upper airway. 01 patient of oropharyngeal burns was also evaluated to rule out upper airway thermal burns. All paediatric airway cases were meticulously evaluated using a structured approach including detailed history, clinical examination, investigations, fibreoptic laryngoscopy, laryngotracheobronchoscopy and appropriate imaging. Appropriate treatment was given after ascertaining diagnosis in all cases.

\section{CONCLUSIONS}

Management of a child with stridor is a challenge for the treating team. We should keep in mind that every paediatric case of stridor does not imply an underlying pathology. A systematic approach and keeping all the possible differential diagnoses in mind are the most important steps in achieving optimum results. 


\section{REFERENCES}

[1] Celmina M, Paule S. Stridor in children. Breathe (Sheff) 2018;14(3):e111-e17.

[2] Clark CM, Kugler K, Carr MM, et al. Common causes of congenital stridor in infants. JAAPA 2018;31(11):36-40.

[3] Saravanam PK, Manimaran V. Flexible laryngoscopy in management of congenital stridor. Indian Journal of Otolaryngol Head Neck Surgery 2017;69(4):509-13.

[4] Ryan SE, Beyerlein L, Lee JH, et al. An unusual Cause for intermittent stridor and dysphagia in an infant. Pediatric Emerg Care 2018;34(8):e139-e40.

[5] Ribeiro J, Julio S, Dias C, et al. Supraglottoplasty in children with laryngomalacia: a review and parents' appraisal. Am J Otolaryngol 2018;39(5):613-17.

[6] Vandjelovic ND, Brown JR, Traboulsi HT, et al. Impact of infant supraglottoplasty on quality of life. Otolaryngol Head and Neck Surg 2018;159(3):564-71.
[7] Redondo-Sedano J, Anton-Pacheco JL, Valverde RM, et al. Laryngeal stenosis in children: types, grades and treatment strategies. J Pediatr Surg 2019;54(9):1933-7.

[8] Cuestas G, Rodriguez V, Doormann F, et al. Endoscopic treatment of acquired subglottic stenosis in children: predictors of success. Arch Argent Pediatr 2018;116(6):418-25.

[9] Marston AP, White DR. Subglottic stenosis. Clin Perinatol 2018;45(4):787-804.

[10] Jain A, Singh I, Meher R, et al. Deep neck spaces abscesses in children below 5 years of age and their complications. Int J Pediatr Otorhinolaryngol 2018;109:40-3.

[11] Mathews F, Shaffer AD, Georg MW, et al. Airway anomalies in patients with craniosynostosis. Laryngoscope 2019;129(11):2594-602. 